\title{
PLANTING PERSIMMONS
}

\section{Japanese Variety Requires Pollinizers Under Most Conditions-Few Satis- factory Pollinizers yet found Native Persimmon Can Not be Used, Because of its Incompatibility.}

H. Harold Hume,

Glen Saint Mary, Florida.

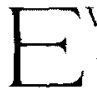

VER since Diospyros Kaki (commonly called the Japanese persimmon) was introduced and established in America about 1875 , it has been noted in many sections that though the trees produce enough flowers to give good crops of fruit, the young fruits or ovaries of many varieties begin to drop shortly after the flowers open, and continue to drop, until, when the harvest season arrives, no fruit remains to be gathered, or so little that the planter is often disgusted with their behavior. In some seasons good crops are produced under conditions quite identical with those which prevailed in seasons when no crop was produced. The cause of this unfruitfulness and this sporadic fruitfulness remained very much of a mystery for many years. Naturally the cultivation of $D . K a k i$ is not regarded favorably by many who have attempted it.

As is usual in such cases, many theories have been advanced to account for its non-fruiting. Some said that the trouble was due to too much cultivation, and that a system of weed or sod cultivation would correct it. Others said it was due to lack of potash in the fertilizer and that heavy applications of potash would correct the trouble. Still others said that the growth and development of the calyces forced the ovaries off, and so on. One theory after another was put to test, but regardless of theories and their application, the Japanese persimmon (Diospyros Kaki) has continued to act in the same manner-: producing flowers abundantly, sometimes resulting in fruit, mọre often giving no harvest.

. WHY FRÜiT FAILS TO SET.

It was'not until 1909 that attention was called to the true cause of barrenness ${ }^{1}$ in $D$. Kaki and the year following; the cause of sporadic fruitfulness was learned. It was known years before to a few ${ }^{2}$ that the flowers of $D$. Kaki are of two kinds, pistillate and staminate, but that this fact had any practical bearing on the problem of unfruitfulness did not seem to occur to anyone. More recently $y^{3}$ the existence of perfect flowers, i.e., those containing both stamens and pistils, was brought to light. These flowers have no practical bearing on the problem, as they are rare and, from some cause or other not yet clearly understood, their ovaries very seldom develop into mature fruit. Since 1909, the results of more than twenty thousand hand pollinations have fairly demonstrated that pollination will cause fruit to set and grow to maturity, when without it, no fruit would be produced.

The fruitfulness of certain trees or groups of trees in some seasons and not in others even when pistillate flowers

${ }^{1}$ Hume, H. Harold. Non-fruiting of Japan Persimmons due to lack of Pollen. Science, N. S. Vol. XXX No, 76. Sept. 3. 308-309, 1909.

${ }^{2}$ Berckmans, P. J. Persimmons. Cyclopedia American Horticulture, 3. 1281. 1901; also Van Deman, H. E. The Kaki. Report of the Commissioner of Agriculture, 1887. $642-645$. 1888 .

3Hume, H. Harold. The flowers of Diospryos Kaki L. F. Trans. Acad. Science St. Louis Vol. XXII. No. 5. Dec. 31. 125-135. Pl. XXV-XXXI. 1913. 


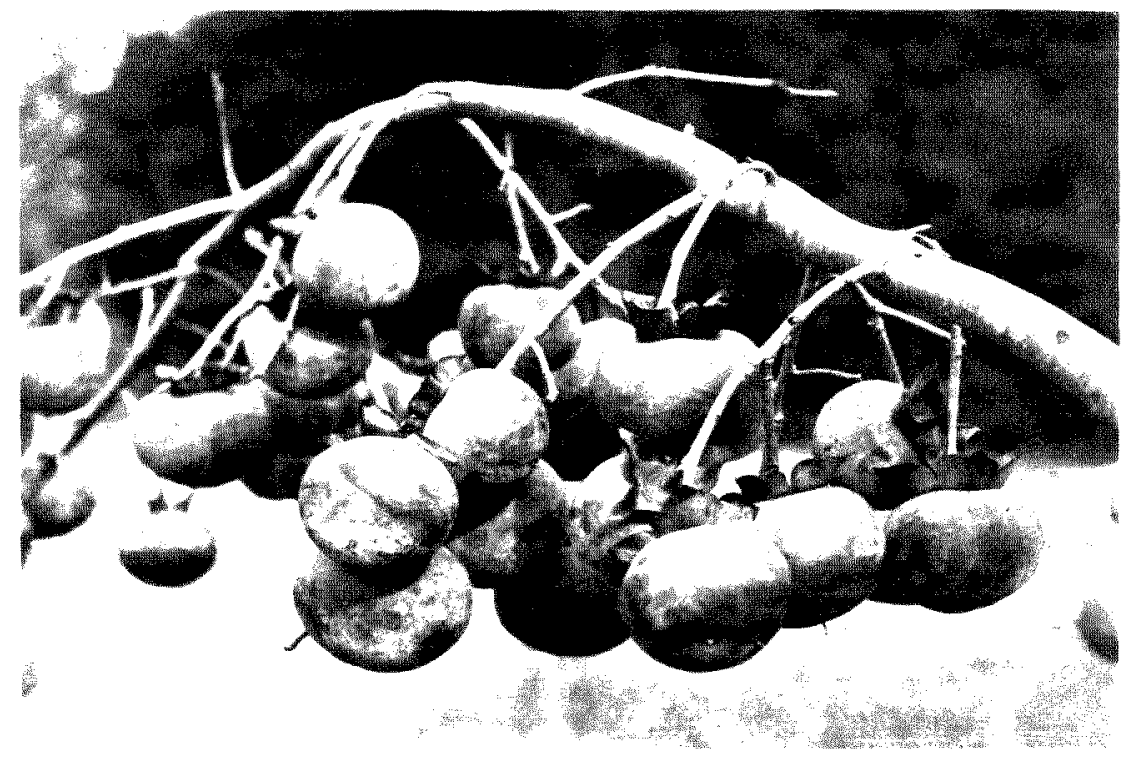

FRUITING" BRANCH OF SIANG.

This variety (S. P. I. No. 21910) produces flowers of hoth sexes, and the persimmons here shown are from pistillate flowers pollinated from staminate blossoms on the same tree. So heavily fruited was the whole tree, that the fruit would have been much improved by thinning. (Figure 16.)

were present in goodly numbers each season can now be explained by the fact that there are certain horticultural varieties of $D$. Kaki which produce staminate flowers at irregular intervals. They may be found on certain trees one season and not the next. Many seasons may elapse before they appear again. It may even happen that never again are they produced, or they may be produced every other season. Many combinations of intervals or skips in the production of staminate flowers are possible and probable. A number of them have been observed and noted with reference to particular trees. The staminate flowers, when they occur on these trees, are abundantly supplied with pollen and fertilize not only the pistillate flowers on the same trees, but through the agency of insects the flowers of many trees surrounding them. Careful examination of many hun- dreds of blossoms of the pistillate type showed that the stamens of these flowers are always abortive, and no pollen is produced in them. It was also learned that the flowers which contain pollen-bearing stamens are always different in structure from these pistillate flowers, so different indeed as to be readily distinguished from them.

THE SEARCH FOR POLLINIZERS.

Having then arrived at the large general catuse of the unfruitfulness of $D$. Kaki and having determined that pollination would cause the trees to hold their fruit, our difficulty was to find dependable staminate flowering sorts. So far as any one in America knew, these did not exist, but it was believed that there were such trees. By accident one tree of unknown name and origin was found near Eagle Lake, Florida. It is dependable. One other 


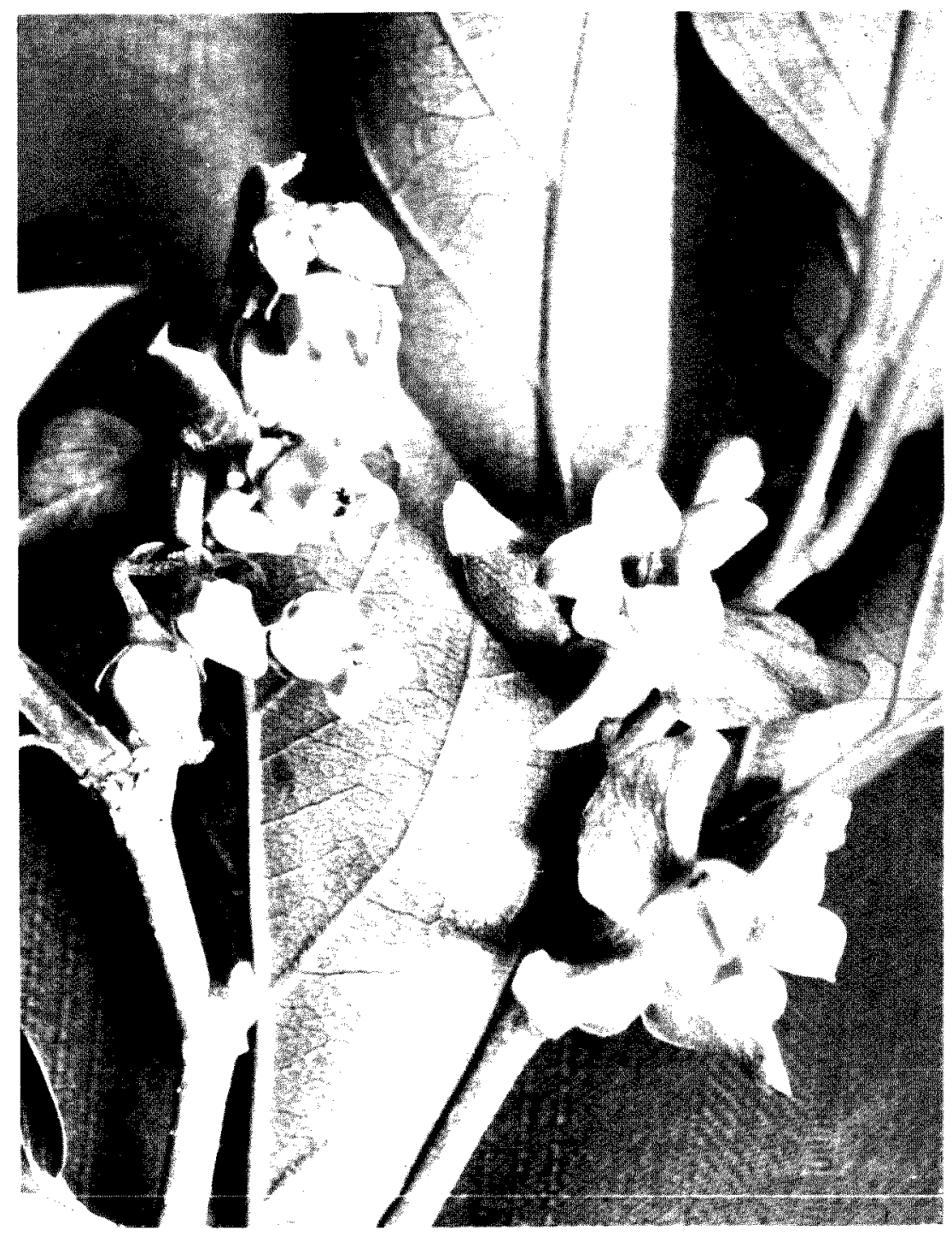

FLOWERS OF THE GAILEY TREE.

This Japanese Persimmon tree has been under observation since 1909, and each year has produced a very large percentage of staminate (male) flowers of the type shown at the right, wide open. The normal, pistillate (female) flowers are seen at the left, wide open. All trees propagated from this parent have likewise borne staminate flowers, and it may therefore be considered the most reliable pollen producer which has yet been developed in the United States. (Figure 17.) 
from San Antonio, Texas, is promising and a third, a seedling at Glen Saint Mary, Florida, is known to have produced staminate flowers each season for three years. Through the efforts of David Fairchild, whose hearty interest and co-operation in the work has been of the greatest help, a number of other promising sorts have been secured from China and Japan. In a few seasons more, it will be known whether these sorts can be depended upon to produce staminate flowers abundantly every time they bloom.

Now, the question is not, "How does Kaki behave in Japan or China? And are pollinizers necessary there?" But the question is, "How does it act in the United States?" and to narrow it down still further, "Is it fruitful in Florida, or Georgia, or California?" Yes, and still more, "How does it behave in a certain county, on a certain farm, or in a certain dooryard?" And the answer must be that while in some localities pollinizers may not be necessary, under other conditions the planting of them is an absolute necessity, making, as it does, the difference between success and failure in securing crops of fruit; and in all cases the presence of pollinizers is an insurance against unfruitfulness.

\section{BEHAVIOR VARIABLE.}

It must be emphasized that the behavior of $D$. Kaki in its relation to pollination, or of any other fruit for the matter of that, in any one locality, is no index to its behavior under any other set of conditions. Even though the conditions may appear to be the same, there are differences which we are too dull to detect or too ignorant to understand, but which nevertheless operate on the trees and influence the results. It is a matter of observation that under certain local seasonal and climatic conditions some varieties of $D$. Kaki will set good crops of fruit without pollination (seedless of course) while under. another set of conditions they do not do so. One season they may bloom freely and set all the fruit the trees should carry and with an equal amount of bloom in another season the same trees may bring no fruit to maturity.
To sum up the conditions as they are at present in the Lawer South, and based on numerous observations extending over more than a decade, it is a fact that trees of all varieties of $D$. Kaki, in good health and which bloom under normal weather conditions, can be depended upon to bear good crops if pollinated, and it is equally true (a few varieties only excepted) that they will not do so if pollen is not provided. In the last two seasons it has been amply demonstrated that all that is necessary is to have staminate flowering trees in proximity to the pistillate ones and bees, wasps, flies and other insects will take care of the problem according to nature's own plan.

\section{POLLINATION NOT A CURE ALL.}

It must not be: concluded, however, from these remarks that pollen bearing trees in a Japanese persimmon orchard are a cure for each and every case of unfruitfulness. There are other factors which enter into the problem of barrenness. The trees may not bear fruit because they are unhealthy-they may be poorly nourished or they may be suffering from attacks of insects, (the flat headed borer, Dicera obscura, in particular) or fungi or bacteria. Again the trees may not even bloom, and the forces which make for flower production, intimately bound up as they are with environmental pressure on the activities of the protoplasm, are not well understood. But if the trees are in good condition, not starved on the one hand, and not forced into too vigorous and succulent growth on the other, they can usually be depended upon to bloom. Even though the trees may bloom profusely and both staminate and pistillate flowers are present in the orchard, the activity of insects, upon which pollination depends, may be greatly restricted or completely suppressed by untoward weather conditions. High winds and heavy rains combined make a condition particularly unfavorable for successful and satisfactory pollination, both because the flowers or their essential parts may be injured and because the insect pollen carriers cannot work.

Neither must it be expected that 


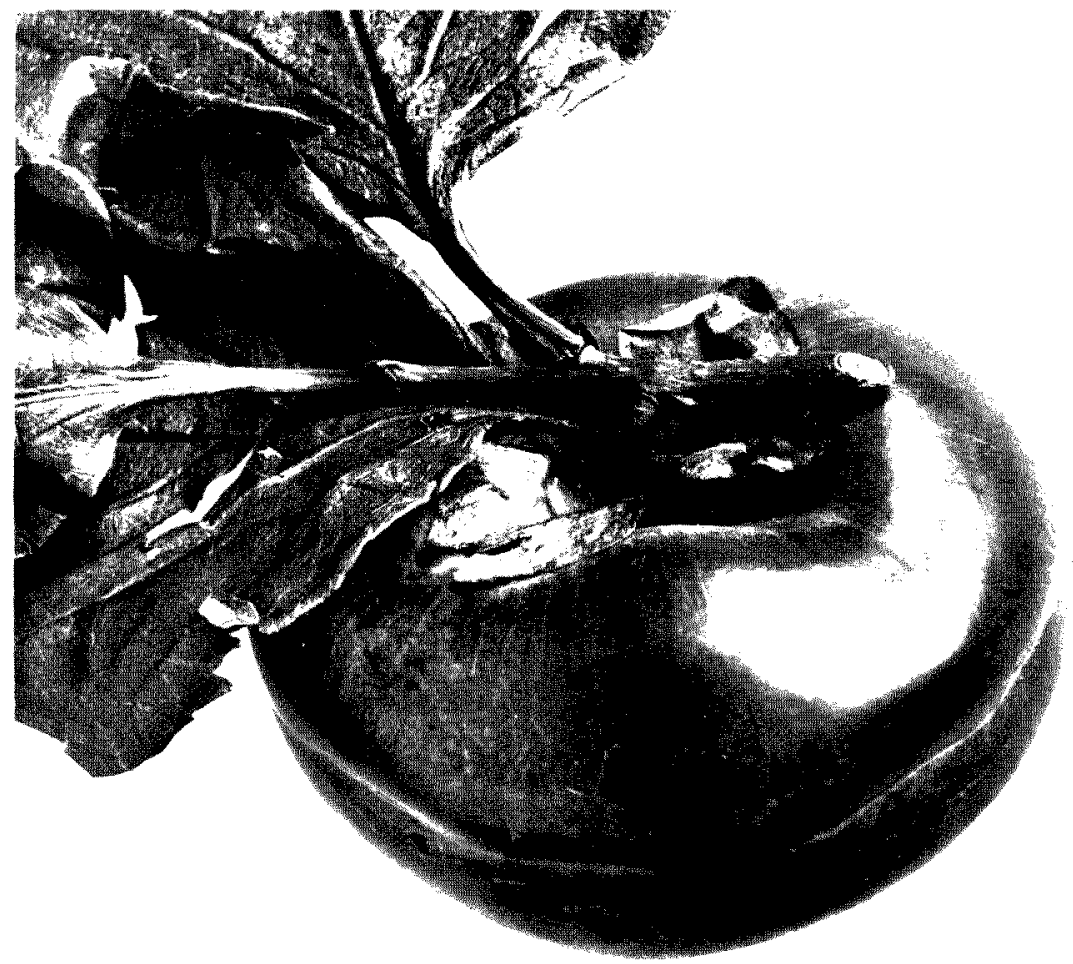

\section{FRUIT OF TAMOPAN VARIETY, ACTUAL SIZE.}

This is one of the most. valuable varieties in China, where it is practically seedless. It is propagated on a large scale by native horticulturists and sold more commonly than any other in some of the most important markets. In the United States it seems never to produce any staminate flowers, but, on the other hand, it seems not to require pollination for successful fruiting. It has not been widely enough tested to determine its behavior with certainty. (Figure 18.)

every pistillate flower on $D$. Kaki trees will set fruit even though there is an abundance of pollen nearby. Pistillate flowers are produced singly in the leaf axils near the base of the twigs of the current season's growth. There may be anywhere from two or three to eight or ten flowers in the lower nodes of a new shoot, and if every one of these flowers produced fruit, the trees would be very much overloaded. Fortunately this does not occur, however, and trees which are heavily fruited do not set more than one fruit for every six or eight flowers on an average. In very much overloaded trees, the number sometimes runs as high as one in three or four. This percentage is too great in some cases and it would be better to remove a considerable portion of the fruit to increase the size and quality of that which is allowed to remain. The percentage of flowers which produce fruit under proper conditions is higher than 
on other fruit trees, where the flowers are borne in clusters, as is the case with apples, pears and plums.

$$
\text { NO HELP FROM D. VIRGINIANA. }
$$

In a very large part of the area in which $D$. Kaki may be grown, the common Ameriean - persimmon,- - D.- Vir.giniana, is native and very naturally the question may be asked, will not staminate trees of this species serve as pollinizers? This the writer thought possible a few year ago. The evidence at hand so far proves that they are entirely worthless for this purpose and necessity of pollinizers for $D$. Virginiana has been denied by some writers.

It follows therefore that to make fruitfulness certain it is a wise plan in all localities to include $D$. Kaki pollinizers in the planting, and with most horticultural varieties of $D$. Kaki, in most sections; it is a provision of fundamental. necessity. What varieties can be used as pollinizers?

Quite a number of varieties of $D$. Kaki are known to produce staminate flowers. The list now known in this country comprises Okame, Taber's No. 23, Taber's No. 129, Gailey, Masugata,

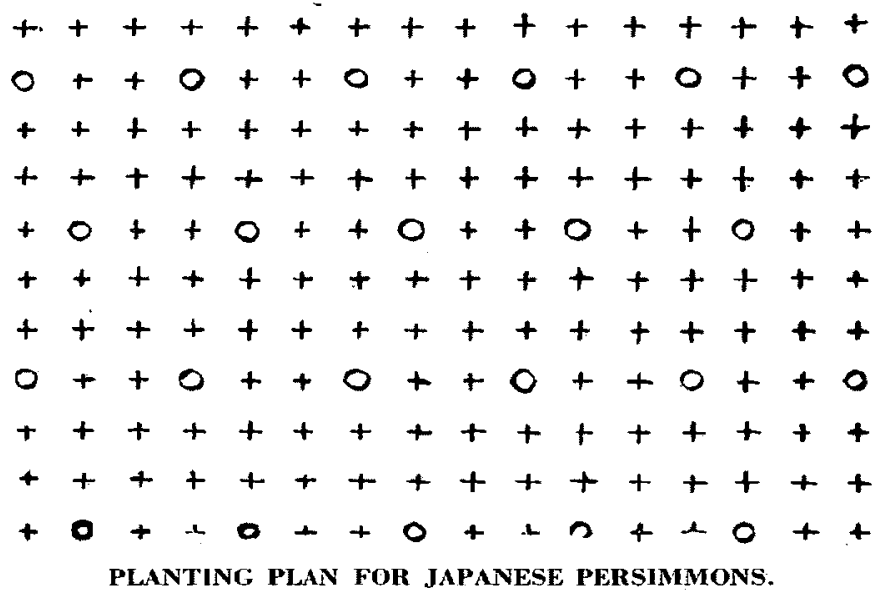

In order that there may be pollinizers wherever wanted, but not elsewhere, Mr. Hume recommends setting them in the positions indicated by small circles in the above diagram, the crosses indicating ordinary female trees. (Figure 19.)

the proximity of staminate $D$. Virginiana trees has no influence whatever on the fruitfulness of $D$. Kaki. Moreover out of many hundred hand pollinations between $D$. Kaki and $D$. Virginiana using both species as the male parent no viable seed has so far been secured. They appear to be absolutely incompatible. It may be pointed out in passing that evidence is accumulating which shows that the presence of staminate $D$. Virginiana trees is essential to the fruitfulness of pistillate trees of the same species in some localities. The
Siang (S. P. I. No. 21910) New Sien (S. P. I. No. 22368) and S. P. I. No. 27037. All of these have produced staminate in addition to the pistillate flowers, and occasionally perfect flowers (i.e., those containing both stamens and pistils) have been found.

Thus far the most painstaking and careful examination of many hundreds of trees, when in bloom, has failed to reveal the presence of staminate flowers on varieties Costata, Hachiya, Hyakume, Tsuru, Tamopan, Tanenashi, Zengi, Triumph, Yemon, Yeddoichi and 
Phelps. Under some conditions some of these same varieties may produce them.

\section{CONFUSION IN NAMES}

It must be remembered, too, that there is much confusion in the names of varieties of $D$ : Kaki dating back to the time of their introduction into America. The older varieties mentioned have been under observation for many years and are believed to be correctly named. Particular reference must be made to Tanenashi, a normally seedless variety which fruits well without pollination. It is very difficult to secure seed in its fruits from the most careful hand pollinations. It would be a drawback to have pollinizers near this variety if the pollen from them caused seed development. Fortunately pollination has practically no effect on it in this particular. The ovules have so far proved to be largely sterile. There is some evidence to prove that Tamopan is very similar to Tanenashi in its behavior toward pollination.

Unfortunately very few of the varieties which have produced staminate flowers can be depended upon as pollinizers. Okame, Taber's No. 23 and Taber's No. 129, for instance, produce staminate flowers one year and not the next, though pistillate flowers are borne each season. Of these three Taber's No. 129 is the most constant in its behavior. Gailey (as the tree found near Eagle Lake has been named) is known to be a constantly staminate variety, i.e., it produces a good percentage of staminate flowers every time it blooms. The other varieties mentioned cannot be placed at this time as they have not been under observation long enough. The lists will doubtless be largely increased within the next few years as the behavior of new introductions becomes known. Seedlings are also being raised and doubtless they will add to the number.

Hence the only variety which can be recommended at this time, as a pollinizer, is Gailey. This variety has a long flowering season, and the flowers are abundantly supplied with pollen. The fruit, however, is quite small, and consequently not so valuable as the larger sorts with which it would be planted.

PLANTING PLANS.

For this reason, and for another reason which will be touched upon later, the number of Gatkey pollinizers in the orchard should be reduced to a minimum, having in mind at the same time that enough trees should be set to produce the pollen necessary to insure good crops of fruit. While it is a recognized fact that pollinizers are necessary in plantings of other kinds of fruits such as apples and pears, for instance, it is also a fact that specific recommendations as to the number of pollinizers required and their location in orchards of these kinds have seldom been made by writers on this subject:

The full complement of seeds (eight) is objectionable in fruit of $D$. Kaki, particularly in the smaller varieties. If one seed develops in a fruit, its development appears to be quite as efficient in causing fruit to hold as if the full number is formed. It has been observed, moreover, that as the distance of a tree from the pollinizers increases, the average number of seeds in the fruit decreases. Therefore to reduce the number of seeds in the fruit to a miminum, the number of pollinizers should be reduced to the very least number which will provide for effective fruit setting. This problem has not yet been worked out absolutely and additional time will be required to decide it definitely.

Plantings made this winter have been made according to the accompanying diagram. It will be noted that the pollinizers are placed every third tree in every third row, in such a way that the spaces in the pollination rows are broken. The proportion is one to seven or eight. In large plantings by this plan, each tree requiring pollination has a pollinizer, directly adjoining it on one side. It may be that a lesser number will in the end prove satisfactory, but there is no doubt but that this plan will insure sufficient pollination for even the most pronounced sterile varieties such as Hachiya and Yemon. 
TOP-WORKING.

What is the owner of an orchard already planted to do if he desires to place pollinizers in his orchard? It is quite easy to bud over branches here and there in properly placed trees. No preliminary cutting back is necessary as the buds may be inserted where the bark is anywhere from one to three years old. The work should be done just as the leaves are coming out in spring, using the ordinary method of shield budding and tying the buds in place with waxed cloth. The wraps should be left on about three weeks and as soon as the buds have taken, the branches should be cut back, leaving stubs five or six inches long to which the shoots from the buds may be tied as they grow out. These stubs should be removed at the end of one season's growth.

\section{ITALIANS TAKE UP EUGENICS}

On November 17th, the Roman Society of Anthropology organized an "Italian Committee" for the study of eugenics. The Directors are.

Prof. Giuseppe Sergi, President.

Prof. Sante de Sanctis, Vice-President.

Dr. Cesare Artom, Counsellor.

Prof. Corrado Gini, Counsellor.

Prof. Mangiagali, Counsellor.

Prof. Alfredo Niceforo, Counsellor.

Dr. F. Umberto Saffiotti, Secretary.

\section{INTERNATIONAL EUGENICS CONGRESS}

The Organizing Committee of the Second International Eugenics Congress met in New York City, January 2,1914 and elected Professor Alexander Graham Bell Honorary President and Professor Henry Fairfield Osborn, President. The nucleus of a General Committee was also named. Professor Osborn has accepted the Presidency. It is probable that the Congress will hold its meetings in the latter half of September, 1915, at the American Museum of Natural History, New York City.

\section{A. B. A. PUBLICATIONS WANTED}

On the inside back cover of this issue will be found a list of the American Breeders Association annual reports, and back numbers of the American Breeders' Magazine, which the association still has for sale. There is a constant demand for the other numbers and reports, particularly from libraries which wish to complete files. Those who have any copies of the annual reports, or of the magazine, other than are enumerated on the inside back cover, will confer a favor by notifying the secretary, if they are willing to sell them. 